\title{
A lung function information system
}

\author{
A.F.M. Verbraak, E. Hoorn*, J. de Vries*, J.M. Bogaard and A. Versprille \\ Lung Function Laboratory, Department of Pulmonary Diseases, University Hospital \\ 'Dijkzigt', Dr. Molenwaterplein 40, 3015 GD Rotterdam and *Central Research Workshop, \\ Erasmus University, Rotterdam, The Netherlands
}

Received January 1990, accepted May 1990

\begin{abstract}
A lung function information system (LFIS) was developed for the data analysis of pulmonary function tests at different locations. This system was connected to the hospital information system (HIS) for the retrieval of patient data and the storage of the lung function variables of patients to generate follow-up reports and to support financial and administrative management. The application programs were developed in such a way that high flexibility was obtained with respect to the patient-computer-technician interaction. The sampled data are stored on a disc to correct earlier decisions, perform recalculations and reanalyse the data for research purposes. When the measurements performed on a patient are authorized, the sampled data are deleted, except for when they are needed for future research. A distributed computer system was chosen to combine the benefits of a centralized system with those of several stand-alone systems. The main tasks of the central unit are to store collected data and computer programs, generate a final lung function report on laser printer and provide a connection to the HIS. In the satellite computers, which are located close to the lung function equipment, the signals and raw data are processed. Furthermore, the satellite computers were in use for program development and sezeral research projects, and for the offline data processing of the lung function measurements from two other haspitals by means of a modem connection. The LFIS improved the quantity and quality of data acquisition. It resulted in an increased capacity of about $50 \%$ concerning spirometry, and facilitated time-consuming complex analyses. It also avoided miscalculations and mistakes in reports previously experienced with hand calculations.
\end{abstract}

Keywords: Lung function, medical informatics, computing, follow-up

\section{INTRODUCTION}

In 1964 Schonfeld et al. ${ }^{1}$ described the use of computer techniques for the analysis of the pulmonary function measurements; since then many such programs have been developed. Progress in the application of automatic data processing has run in parallel with the development of the technical facilities and in many of the first systems remote computers were used for the analysis of the data ${ }^{2-4}$. In the first development the signals, the patient number and the spirometer calibration factor were stored on magnetic tape and processed afterwards $s^{1,2,5}$. Next, online processing was established through connections between equipment and remote computers ${ }^{6-8}$. Programs for the calculation of the lung function values of hand measured data and the generation of a lung function report have been published by several authors ${ }^{7,9-15}$. Stand-alone real-time systems were described for either clinical routine or research objectives. Examples of these are the flow-volume curve and spirography ${ }^{16-18}$, the bodyplethysmography ${ }^{19-21}$, meas urements of lung compliance ${ }^{22}$, and exercise testing $^{23-26}$. In many respects the automation improved the data processing substantially ${ }^{27}$ and several authors have investigated the potential benefits $9,11,18,28$.

Correspondence and reprint requests to: Mr A.F.M. Verbraak

(C) 1991 Butterworth-Heinemann for BES

$0141-5425 / 91 / 010027-08$
To our knowledge no integration of the various types of measurements at different locations in the lung function laboratory have been published, let alone for a system connected to a hospital information system (HIS). We aimed to develop a lung function information system (LFIS), including its connection to the HIS, to serve the data processing of a wide variety of lung function routines and research measurements, and in addition to serve administrative procedures. The development implied two stages: the offline automatic processing of data obtained by hand from the signals of lung function tests; and the online real-time data processing on the signals.

In this paper we describe the concepts of the system, its hardware and software. Furthermore, we evaluate the profit in time and the improvement in quality compared with the conventional by hand situation.

\section{METHODS}

In industry and other research centres no proper software package has been available to fulfil the requirements of an LFIS. Available software developed by the industry, was only suitable for their particular lung function equipment and the sources of their programs were not available. Therefore, we 
could not adapt their software to our specifications and we had to develop our own integrated system.

First, we defined the general requirements for the automatic data processing.

\section{General requirements}

The input of patient data had to be done at the administration desk as well as in the different laboratory rooms. During the measurements the lung function technician had to control the measurement procedures and check online the results of the manoeuvres. Therefore, a real-time calculation and a graphic presentation of the most important signals on the graphical terminals (Figure 1) were conditional for the lung function technician to be able to judge whether maximal values of several variables were obtained.

Maximum flexibility in the software program was necessary to define an individual program of measurements adapted to the specific conditions of a patient. This flexibility had to include the ability of the technician to change the selection afterwards and append values from other measurements.

The results of the measurements performed in the different rooms had to be presented alphanumerically as well as graphically in a final report. The connection to the HIS delivered the general data concerning the patient.

\section{Realization of the system}

At the time of writing the system was composed of one central computer and seven satellite computers, each attached to the lung function equipment. The benefits of a centralized system were combined with those of several stand-alone systems ${ }^{29}$. The main advantages of this approach can be listed as follows:

1. Centralization of expensive devices, databases, and software;

2. Gradual development of the system corresponding to the automation of new pulmonary function tests;

3. Expansion of the system dependent upon an increasing load on the pulmonary function laboratory as well as on the development of new measurements;

4. Parallel data processing of measurements in the satellites which guarantees a fast system response;

5. A relatively modest central system;

6. A relatively small vulnerability of the total system, which guarantees a continuous service of the pulmonary function laboratory.

During disorders and maintenance of the central system a satellite can be used instead, and during the breakdown of a satellite only one unit of lung function measurements is out of action without affecting the overall service of the laboratory.

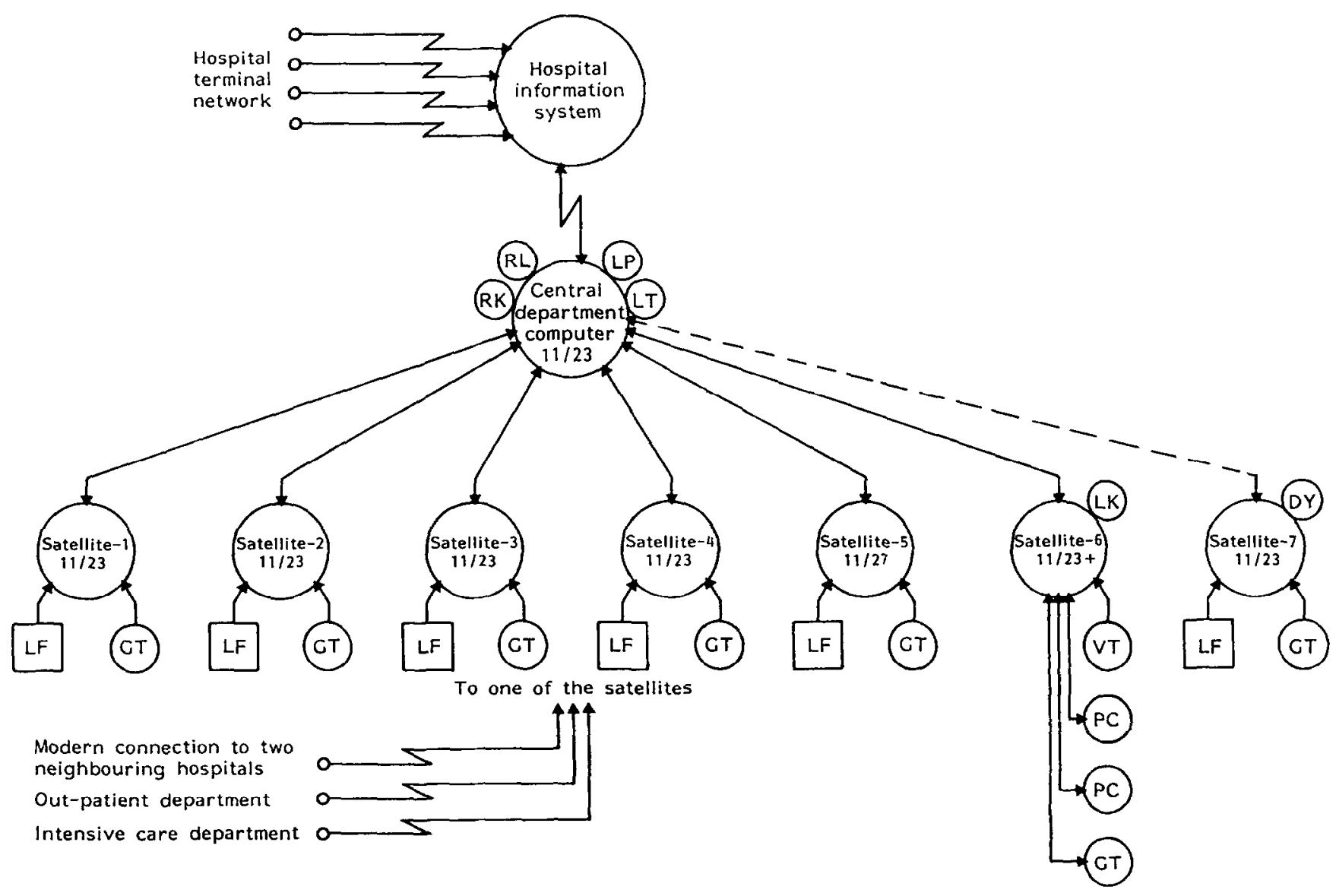

Figure 1 Distributed computer system of the pulmonary function laboratory. DY, floppy disk (0.5 MByte); GT, graphic terminal; LK, hard discs (40 Mbyte); LF, lung function equipment; LP, laser printer; LT, matrix printer; PC, personal computer; RK, hard discs (7.5 Mbyte); RL, hard discs (25 Mbyte); VT, Video terminal. 11/23, 11/23+, 11/73, PDP-11 computers 
Table 1 System file

\begin{tabular}{ll}
\hline Item & Options and scttings \\
\hline General & $\begin{array}{l}\text { Version of system set-up, current date, last } \\
\text { time the system was used, barometric } \\
\text { pressure, minimal and maximal allowed } \\
\text { laboratory numbers, current laboratory } \\
\text { number }\end{array}$ \\
Allowed programs & $\begin{array}{l}\text { Names of the programs } \\
\text { HIS communication }\end{array}$ \\
User name of the systern, password of the \\
system, location code, session type (test/ \\
production), log-in flags, time-out flags \\
Last date when major change in follow-up \\
report was made
\end{tabular}

Commercially available hardware and system software were selected as far as possible.

\section{Application software}

The programs were written in FORTRAN and for some special functions (e.g. A/D conversion), an assembler language was used. The software was structured in such a way that it can be adapted to the changes in hardware and in the requirements of the software.

The information concerning the system configuration is defined at two levels. First, the system file (Table 1) contains all the variables and settings that are common for all satellites, e.g. the barometric pressure and the settings for the communication with HIS. Second, the satellite file (Table 2) contains the specific information for each workstation, such as the type of computer hardware in the satellite and the identification of the lung function equipment connected to the satellite and the laboratory number of the patient to be tested.

The start-up procedure and the execution of the application programs are adapted to the settings stored in the system and satellite file. Through information stored in these files, a mixture of different types of hardware is supported by the software, which avoids the development of specific programs that are only valid for a specific hardware configuration.

Additionally, a chaining facility is supplied by the system software to enable a program to call another program directly without input from the laboratory technician. To avoid the need for input of already known data by the technician, a common area in the

Table 2 Satellite file

\begin{tabular}{ll}
\hline Item & Options and settings \\
\hline $\begin{array}{l}\text { Equipment set } \\
\text { Terminal type }\end{array}$ & $\begin{array}{l}\text { Several lung function devices per satellite. } \\
\text { Graphic terminal (Tektronix 4025, } \\
\text { VT240), alpha-numeric (VT 100) } \\
\text { Room number where the satellite is } \\
\text { Room number }\end{array}$ \\
$\begin{array}{l}\text { Laser }(\mathrm{LN}-03), \text { Matrix (MT-85) } \\
\text { Default printer }\end{array}$ & $\begin{array}{l}\text { Normal, inverted } \\
\text { Aata switches }\end{array}$ \\
A/D convertor & $\begin{array}{l}\text { programmable gain, fixed gain } \\
\text { Programmable, fixed frequency }\end{array}$ \\
Real-time clock & $11 / 03,11 / 23,11 / 73$, (No) floating-point \\
Processor & hardware
\end{tabular}

memory is used for exchange of variables between programs. The chaining facility is implemented at five levels. The first program in the chain has the highest level. When a program in the chain is started it checks whether it has been activated by another program in the chain or by a technician. When it is activated from another program it checks whether it is called from a higher or a lower level. Then the program reads the data from the common area in the memory and controls whether it is started at its beginning or at some other point. This latter option enables whole programs to be used as subroutines in other programs.

A maximal flexibility in the patient-computertechnician interaction was a main problem in the online automatic data processing. Function keys and a menu structure were used for the communication between computer and technician. Parameters already known can be passed as much as possible from one program to another. Switches of the lung function equipment and a special switch panel are read by the program to activate options in the program. These switches control the routine measurements. Moreover, special options can be activated for research and debugging facilities. Such a set-up requires minimum attention from the technician to the computer system during the measurements.

It is essential that all data stored in the HIS are correct. Therefore, the technician has many possibilities to correct earlier decisions and cancel or change variables. These alterations are a prerequisite for an automated system to have a correct database.

\section{System hardware}

The hardware of the system was based on LSI-11 processors (Digital Equipment Corp., MA, USA). Standardization in the hospital was based on this type of computer, which facilitated the start of the automatic data processing (e.g. the transfer of offline programs from a remote computer to the new system of the department). The development was initiated with one stand-alone system incorporating a mass storage device, a real-time clock, an A/D converter, a digital input and output module, a printer and a graphical terminal. This system was used to demonstrate the feasibility of the data processing according to the requirements mentioned previously. Using the same bus structure for the central computer and the satellites we could transfer the components necessary for the real-time data acquisition from the stand-alone system to the satellite, and the stand-alone computer was upgraded to the central system. In the total network, as presented in Figure 1, three specific function levels can be distinguished:

1. The HIS cunsists of a twin system (VAX 11/785) with more than 800 terminals. It provides the general patient data to the LFIS for integration with the measured lung function data. Moreover, the HIS is used for long-term storage of lung function data which must be available online.

2. The central department computer functions mainly as a management computer for all satellites. It contains those devices that can be shared by the satellites. The system consists of a processor 
(PDP 11/23), memory (32 kw), background memory (25 Mbyte), console terminal (LA36), laser printer (LN03-plus), needle printer (MT 85) and communication lines to the HIS and to the satellites.

3. The satellites handle the online and offline program execution under direct control of the lung function technician. The satellites contain the facilities for the A/D conversion, the read-out of equipment switch settings and a high resolution graphic display $(640 \times 480$ pixels $)$.

In principle these satellites contain no facilities for the storage of programs and data. In the satellites the processors, the memory, the A/D converter, the realtime clock and the attached terminal are of different types. Although the satellites have prescribed tasks, their possibilities can be extended with special functions such as a $\mathrm{D} / \mathrm{A}$ convertor and a floppy-disc drive. One of the satellites, number 6 , is used for offline activities (e.g. for the administration desk and for program development). It functions also as a back-up system for the central computer. This satellite is equipped with a local Winchester disk (CDC-Lark, 20 Mbyte) and magnetic tape (Cipher 891-2). Additionally, a personal computer (PC) is connected to it. Mainly this PC is in use for exchange of files, text processing and statistical analyses.

\section{System software}

The system software is based on commercially available packages. Basically it is an RT-11 (Digital Equipment Corp.), a single-user, real-time operating system with a foreground-to-background monitor. On top of this the STAR-11 (Hammond Software, Göttingen, Germany) package is run. In the host, STAR-11 handles in the foreground the communication with the satellites, while the background can be used for application programs or software cache. A maximum of 16 satellite systems can be served by this operating system. At the time of writing we had connected seven systems. In each satellite at least one RT-11 workplace is created. By means of the system software SHARE-11 (Hammond Software) a multi-user environment was created in satellite number 6 . As pointed out earlier, this satellite is used for none-time critical functions. Finally, satellite 7 can be used as a stand-alone system or as a satellite.

\section{Organization of data acquisition}

The patient routine measurements, administration and patient-linked research at the pulmonary function laboratory are reviewed in Figure 2. On arrival the patient is registered in the laboratory system and a laboratory number is given as a reference for all measurements to be performed. Then, the patient data are read from the HIS and stored as a patient file in the laboratory system. When no patient data are available from the IIIS a local input is made. Information that is important for the lung function tests and the final report, such as the anthropometric data of the patient, the

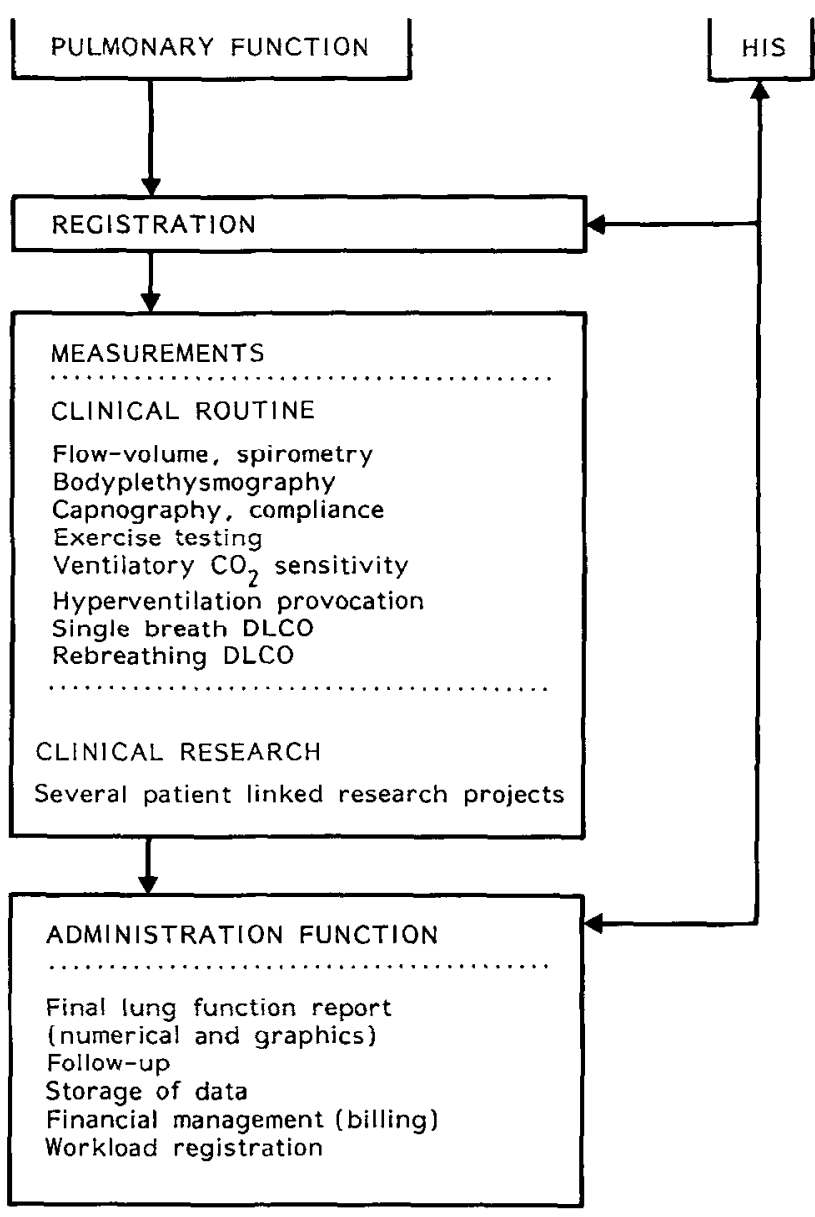

Figure 2 Organization of data acquisition and financial and administrative procedures at the pulmonary function laboratory

preliminary diagnosis and the name of the physician who requested the tests, are added to the HIS data. When the patient has been tested previously, the essential information for the performance of the next testing is automatically transferred from the HIS to the laboratory system. Such information indicates the presence of spirometry-induced asthma, the necessity of using the arm span as a measurement of length for patients with scoliosis, the level of cooperation of the patient, and any language problems. The information that is important for the next test is indicated and stored in the HIS. Furthermore, during the measurements the patient file in the laboratory computer is updated with information for financial administration and workload registration.

A broad spectrum of programs is implemented in the laboratory system, these are used for either clinical routine or research, e.g. spirometry, flow-volume, bodyplethysmography, capnography, compliance, exercise testing, ventilatory $\mathrm{CO}_{2}$ sensitivity, hyperventilation provocation testing, single breath diffusing capacity for CO (DLCO) and rebreathing DLCO. The online and offline programs can be performed in different rooms and different sequences. The sampled signals and the calculated data, relevant for the technician to guide the patient through the measurements, are displayed on the graphical terminal. During the measurements the values obtained are compared with their reference 
values. Each computer program creates at least two files. One binary file is used to store all sampled data together with a logging of activities undertaken by the technician for the technical control of the measurement process. Storage of the signals and the logging enable an offline recalculation. In addition, the stored signals can be used for specific research projects. In the second binary file, the result file, the calculated data, which will be integrated in the final report, are stored. Moreover, additional files can be created either for additional calculations and research purposes or for integration of graphics information in the final lung function report.

Maximal accuracy and reliabilty guarantee long-term use of the database and therefore, corrections of the measured data have to be done before the final lung function report is printed. All programs for online data acquisition in routine lung function have an additional offline program for processing hand-measured functions either to change or delete values obtained online. Selection and rejection of manoeuvres and calculated data can be done during and at the end of the series of measurements. The various decisions made by the technician are supported by the program. The technician can always overrule the computer.

In the final lung function report, the results of the lung function tests are compared with their reference values. The interpretation of the data can be typed by the secretary through a standard text processor and can be included in the final report. When necessary the values of the previous tests are read from the HIS, linked up with the new data and generated into a follow-up, graphically presented over a time span of 1,5 or 10 years. Some variables are presented as a percentage of their reference values (Figure $3 a$ ), other data are plotted in absolute values (Figure $3 b$ ). The effects of a bronchodilator are also indicated.

Finally, the measured values are authorized and stored in the HIS. In addition, the workload registration and the financial administration is transferred via the HIS. Each morning a back-up of the result files of the preceding day is made on another disc. The other files are also copied to another disc and removed from the routine disc. These files are only stored for 1 day. A different procedure can be followed for special research measurements; these files could be copied to a special disc or magnetic tape for further analysis at a later date.

\section{RESULTS}

The automatic data processing in the lung function laboratory resulted in an increase in quantity and an improvement in quality of the lung function tests.

\section{Increase in quantity}

To estimate the gain by automatic data processing with respect to conventional situations, we have calculated the time necessary for the performance of measurements and data analysis for three situations.

1. In the conventional situation where the technician has to do all data processing by hand, including the writing of the final results in a final pre-printed report.

2. $\Lambda \mathrm{t}$ the first stage of automatic data processing in which the raw data of the measurements were calculated offline and automatically printed in a final report, including comparison with reference values.

3. Utilizing full online data processing from measurements to the final report.

Table 3 shows the increase in capacity, as related to the automatic data processing, for the set of four measurements that are performed most frequently. The number of tests performed on patients is normalized with respect to the number of spirometric measurements executed annually. The weight factor is the number found by dividing the total number of measurements of each type by the number of spirometry measurements, which was 3500 in 1987. Thus, the number of $\mathrm{CO}$-diffusion determinations was $0.17 \times 3500=600$. The measurements and the calculation time were connected to the weight factors to get a weighted gain of time for the four types of
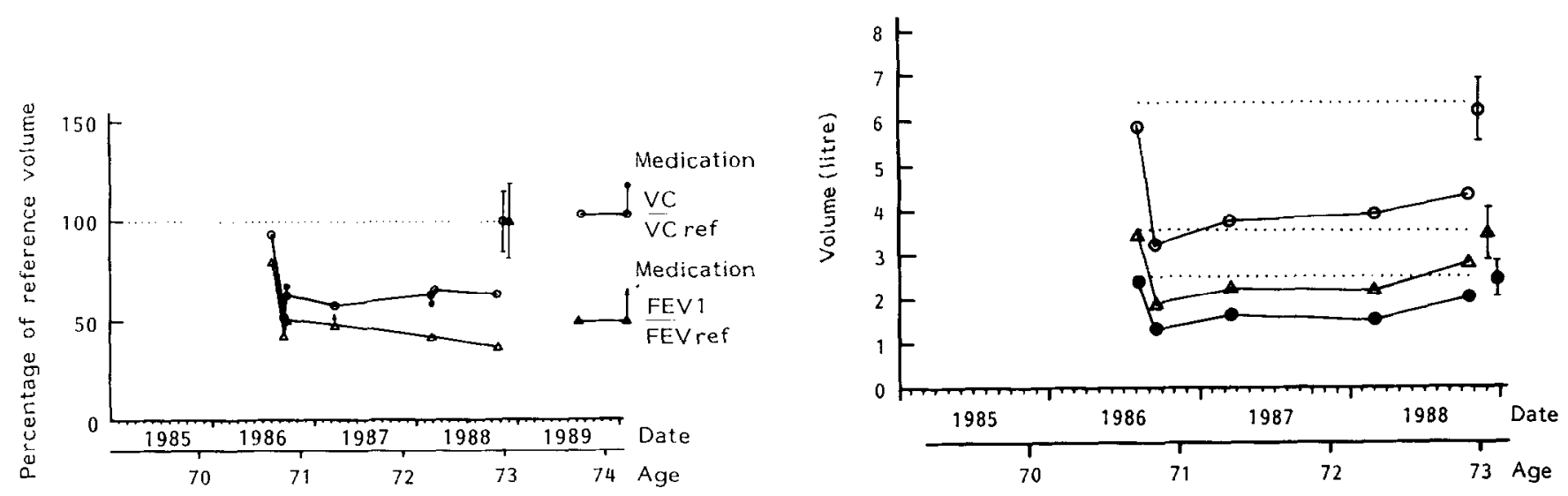

Figure 3 Follow-up reports representing: a, the change of the forced expiratory volume in $1 \mathrm{~s}$ (FEV 1 ) and vital capacity (VC) and the changes after medication with a bronchodilator (data are given in percentage of the reference values) and; $b$, the absolute values of total lung capacity (TLC), $O$; functional residue capacity (FRC), $\Delta$; and residual capacity (RV), 0 ; together with the reference values and the standard deviation for the reference values indicated by bars (the $x$ axis can be plotted over a time period of 1,5 or 10 years) 
Table 3 Gain of time due to automatic data processing (ADP)

\begin{tabular}{|c|c|c|c|c|c|}
\hline \multirow[b]{2}{*}{$\begin{array}{l}\text { Type of } \\
\text { Measurement }\end{array}$} & \multirow[b]{2}{*}{$\begin{array}{l}\text { Weight factor } \\
\text { for measurements }\end{array}$} & \multirow[b]{2}{*}{$\begin{array}{l}\text { Weighted time } \\
\text { for measurements } \\
\text { (min/patient) }\end{array}$} & \multicolumn{3}{|c|}{ Weighted time for calculation and reports } \\
\hline & & & $\begin{array}{l}\text { Conventional } \\
\text { (technician) } \\
\text { (min/patient) }\end{array}$ & $\begin{array}{l}\text { Offline } \\
\text { (ADP) } \\
\text { (min/patient) }\end{array}$ & $\begin{array}{l}\text { Online } \\
\text { (ADP) } \\
\text { (min/patient) }\end{array}$ \\
\hline $\begin{array}{l}\text { Spirometry } \\
\text { Spirometry }\end{array}$ & 1 & 15 & 20 & 10 & 5 \\
\hline after medication & 0.57 & 8.6 & 11.4 & 5.7 & 2.9 \\
\hline Residual volume & 0.57 & 11.4 & 11.4 & 5.7 & 2.9 \\
\hline \multirow[t]{2}{*}{ CO-diffusion } & 0.17 & 5.1 & 3.4 & 2.6 & 0.9 \\
\hline & & 40.1 & 46.2 & 24 & 11.7 \\
\hline $\begin{array}{l}\text { Total time including } \\
\text { measurement time }\end{array}$ & & & 86.3 & 64.1 & 51.8 \\
\hline
\end{tabular}

Decrease in workload from conventional to offline ADP: 0.74 ; offline ADP to online ADP: 0.81 ; conventional to online ADP: 0.60

lung function tests. Thus the real measurement time for a CO-diffusion measurement was $5.1 / 0.17 \mathrm{~min}=$ $30 \mathrm{~min}$. In 1974 the total number of lung function tests was 12543 performed with five technicians. In 1987 the number was 19540 performed with 5.8 technicians.

The time for the measurements is equal for the three situations, and is largely influenced by the degree of illness, intelligence and cooperation of the patient, and by any language problems that may arise. The time values in Table 3 were obtained from the information given by five technicians, and the analyses of the production per technician over a few months in all situations. Our estimation of a gain of about $35 \%(86.3 / 64.1)$ by offline data processing with respect to the conventional situation is in agreement with that of Protti ${ }^{11}$. The numbers indicate a further gain to more than $66 \%(86.3 / 51.8)$ when using online data processing. The total number of tests performed at the laboratory is another indication of the gain of quantity. The profit in the number of tests since 1974 is $34 \%$ when normalized per technician. This number is the overall result of the laboratory, which is smaller than the profit of about $60 \%$ in the spirometry of Table 3. These differences are due to:

1. Correction in the gain by online data processing of other activities than lung function testing per se, whereas no such correction is present in the increase of the number of tests.

2. Introduction of other tests since 1974, such as bodyplethysmography, exercise testing, $\mathrm{CO}_{2-}$ response measurements.

3. Use of another type of bronchodilator, which resulted in an increase in measurement time of 10-15 min because of the greater time delay between administration to a patient and the measurement of the reaction.

4. Performance of measurements for special research projects, which were not performed before that time.

In tests with time-consuming data analyses, such as compliance and bodyplethysmography, the profit in time is much larger when using online data processing.

\section{Improvement in quality}

The offline automatic data processing eliminated incidental miscalculations by hand. The online data processing diminished also the inaccuracies in the sampling of the analogue signal, which was performed by measuring the deflections on the recording paper of the spirometer and other devices by hand. In addition, there is a standardization in the analysis of, for example, the starting point of the FEVI manoeuvre and the calculation of $\mathrm{O}_{2}$ uptake by regression analysis on successive end-expiratory levels from the spirogram. Online data processing implied correction of signals for different types of drift in different types of tests, e.g. slow-pressure drift and temperature drift. The integration of information from different measurements, and the presentation of data together with the reference values (Figure 4), enable a better interpretation of the results. By hand this would cause a significant increase in time (not included in Table 3). The same holds for the generation of the followup report (Figure $3 a$ and $b$ ).

An additional result of the automatic data processing is the introduction of new measurement techniques that otherwise could not be applied routincly and which improve the diagnosis. Examples are the

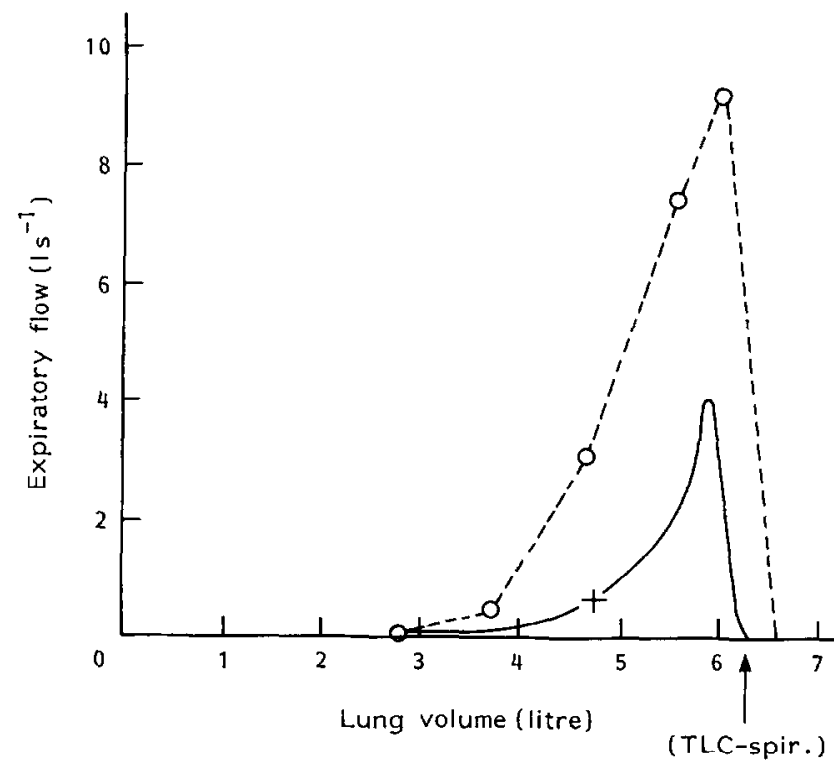

Figure 4 Forced expiratory flow-volume curve of a patient with its reference curve. The curves are plotted 'volume-based', starting at measured TLC (- - ) (by spirometry), and reference TLC $(\mathrm{O}---\mathrm{O})$ respectively. + indicates the FEV1 
online calculation of the effective airway resistance in bodyplethysmography ${ }^{30,31}$, the use of parameter estimation techniques based on model simulations ${ }^{32}$ and, the analysis of the capnography signal, not only against time but also against volum $e^{33}$.

Finally, most values of the different manoeuvres are given online to the technician. Formerly, the technician had to calculate the values by hand between the different manoeuvres to decide whether to stop the measurements or continue to obtain maximal values. The automatic data processing allows the technician to pay more attention to the patient.

\section{DISCUSSION AND CONCLUSIONS}

The benefits obtained from the computerized system are: an improved accuracy and precision of observations and results, the standardization of terminology and format, increased accessibility and availability of patient data, a reduction in observer variation, the provision of individual patient records with multiple observations in a manageable form and an improved legibility of the patient's data report. Moreover, the data stored in the HIS could be used for a wide range of administrative needs, e.g. billing, status reporting and the provision of basic data for the follow-up. The lung function laboratory is responsible for the consistency of the data stored in the HIS. The HIS guarantees a reliable storage of data. Moreover, a back-up is made of the data on a separate local disc at the laboratory.

The introduction of offline automatic data processing has as its main effect an increase in capacity against minimal costs. The additional implementation of online, real-time automatic data processing resulted in a further improvement in capacity, but mainly it improved the quality of measurement and enabled the introduction of new measurement techniques, which could not be otherwise performed. The presentation of measured values and the reference values in one figure improved the interpretation of the lung function tests.

The vulnerability of the LFIS appeared to be minimal due to the decentralized system approach. The central department computer, which is used by all satellites, was kept as simple as possible. Therefore, the risk of breakdown was reduced. If the central system could not be used because of technical or maintenance problems, one of the satellites took over its function and at least three laboratory rooms could remain in routine use. The interchangeability of the system components influenced the reliability of the system as a whole in a positive sense. Down-time due to problems in one of the satellites or cable problems will only affect the satellite involved. In case of severe problems in the host system, it takes 10 min to restart the network with satellite No 6 as the new host system. Through the decentralized system approach, instead of one central computer, it was possible to enlarge the automatic data processing more easily and to follow the newest technology for the additional satellites. In our set-up we made use of the microprocessor (pdp 11/23, Digital Equipment Corp.). Programs are available on certain conditions and after mutual consultation. At the moment new develop- ments are based on personal computers and programmed in PASCAL. In the near future the whole system set-up will be converted to PC-based systems and Ethernet cabling.

In 1988 approximately 20000 lung function measurements were performed on about 4000 patients. Lung function equipment from different manufacturers was used because of the changing demand with respect to specifications and because of the time differences in the purchase of the equipments.

In contrast to other reports ${ }^{\mathrm{I}, 4}$, in our opinion the technician must be specially trained if automatic data processing is introduced ${ }^{1,4}$, as they have a higher level of responsibility. Because the results of the measurements become available online, the technician has to decide during the tests whether to go on with the measurcment, go to the next measurement or to stop. In addition, the technicians have to understand at least the principles of automatic data processing to be able to judge the results given by the computer systems and to be able to see whether the hardware or software functions satisfactorily.

The multiprocessor network, integrated at the department and hospital level, resulted in a flexible and a reliable system. The success of the developed system was partly due to the attention given to the pitfalls in developing a system, as summarized by Friedman $e t \mathrm{al}^{34}$. There has been a strong interaction between the physicians, the lung technicians and computer experts. A division of the projects into clearly separated parts has given well defined results for the department. By the purchase of commercial parts as far as possible, we could limit ourselves to those problems specific to the processing of lung function data. In addition, the hospital management has supported the project to a large extent and continues to do so. To guarantee optimal use of automatic data processing, it must always be possible to change the programs to test and introduce new techniques that follow new medical insights, and take up new demands from the department. This is essential especially in an academic environment.

\section{ACKNOWLEDGMENTS}

This work was supported by a grant from the Dutch Asthma Foundation. The authors are grateful to Dr J.R.C. Jansen who was involved in the initiation of the LFIS and who started the offline data processing, and to the co-workers; C.P. Bakker, T. van Immerzeel and C.J. Jongkind, who contributed to the further development of the programs.

\section{REFERENCES}

1. Shonfeld EM, Kerekes J, Rademacher CA, Weihrer AL, Abraham S, Silver H, Caceres CA. Methodology for computer measurement of pulmonary function curves. Dis Chest 1964; 46: 427-35.

2. Ayers WR, Ward SA, Weihrer ALV, Abraham S, Caceres CA. Description of a computer program for analysis of the forced expiratory spirogram.I. Instrumentation and programming. Comp Biochem Res1969; 2: 207-20.

3. Ayers WR, Abraham S, Ward SA, Weihrer AL, Rosner 
SW, Caceres CA. Description of a computer program for analysis forced expiratory spirogram. II. Validation. Comp Biochem Res 1969; 2: 220-9.

4. Rosner SW, Palmer A, Caceres CA. A computer program for computation and interpretation of pulmonary function data. Comp Biomed Res 1971; 4: 141-56.

5. Derrett CJ, Brown C. A system for processing by digital computer spirograms acquired in field surveys. Thorax 1975; 30: 674-7.

6. Cardus D, Newton L. Development of a computer technique for the on-line processing of respiratory variables. Comput Biol Med 1970; 1: 125-33.

7. Crockett A, Smith RL. Use of on-line computer facilities in a respiratory function laboratory, Med J Aust 1975; 2: 486-9.

8. Ostrander LE. A data communication system for interactive linking of remote computer and laboratory. Med Instrum 1975; 9: 147-9.

9. Naimark A, Cherniack RM, Protti D. Comprehensive respiratory information system for clinical investigation of respiratory disease. Am Rev Resp Dis 1971; 103: 229-39.

10. Chiang ST. Application of desk-top computer in clinical spirometry, an automatic calculation and diagnosis program. Am Rev Resp Dis 1972; 106: 614-7.

11. Protti DJ, Craven N, Naimark A, Cherniack RM. Com puter assistance in the clinical investigation of pulmonary function studies. Methods Inform Med 1973; 12: 102-8.

12. Vogel J, Moller E, Harzendorf E. EDV-gerechte respiratorische funktions diagnostik. Zeitschrift für Erkrankungen der Atmungsorgane 1973; 137: 409-24.

13. Pack AI, McCusker R, Moran F. A computer system for processing data from routine pulmonary function tests. Thorax 1977; 32: 333-41.

14. Sahakian J. A pocket computer program for normal values of selected lung function tests in children and young adults. Comp Biol Med 1981; 11: 231-5.

15. Tanser AR. The use of a micro-computer system in a lung function testing laboratory. $B r J$ Dis Chest 1982; 76: 130-5.

16. Dickman ML, Schmidt CD, Gardner RM, Marshall HW, Day WC, Warner HR. On-line computerized spirometry in 738 normal adults. Am Rev Resp Dis 1969; 100: 780-91.

17. Bunn AE, Vermaak JC, de Kock MA. A comprehensive on-line computerised lung function screening test. Respiration $1979 ; 37$ : $42-51$.

18. Primiano Jr FP, Bacevice Jr AE, Lough MD, Doershuk CF. Computer analysis of slow vital capacity spirograms. Comp Biol Med 1982; 12: 107-17.

19. Sykes TW, Haynes RL, McFadden Jr ER. On-line determinations of lung volumes by plethysmography and digital computer. Am Rev Resp Dis 1977; 115: 581-6.

20. Lorino H, Laurent D, Harf A, Brault Y, Lorino AM, Atlan G. On-line calculation of lung volumes by digital compu- ter from a plethysmographic measurement of ventilatory flow. Med Biol Eng Comp 1980; 18: 291-8.

21. Matthys $H$, Zaiss A, Fischer $J$, Kienzle $P$. On-line programm für die Ganzkörperplethysmographie.AtemwLungenkrankh 1982;8:268-73.

22. Colebatch HJH, Nail BS, NG CKY. Computerized measurement of pulmonary conductance and elastic recoil. J Appl Physiol 1978; 44: 611-9.

23. Beaver WL, Wasserman K, Whipp BJ. On-line computer analysis and breath-by-breath graphical display of exercise function tests.J Appl Physiol 1973; 34: 128-33.

24. Miyamoto Y, Sakakibara K, Takahashi M, Tamura T, Takahashi T, Hiura T, Mikami T. On-line computer for assessing respiratory and metabolic function during exercise. Med Biol Eng Comp 1981; 19: 340-8.

25. El-Dhaher AHG, Ahmad AJ, Hassan TS, Kaouri HA, Mustafa KY. An integrated microprocessor-based system enhanced with graphics for the evaluation of slope ratios and other flow-volume curve parameters. Comp Prog Biomed 1983; 17: 129-36.

26. El-Dhaher AHG, Ahmad AJ, Hassan TS, Mustafa KY. Microprocessor-based system for on-line analysis of respiratory responses to exercise. Comp Prog Biomed 1985; 19: 179-87.

27. Lord PW, Brooks AGF. A comparison of manual and automated methods of measuring airways resistance and thoracic gas volume. Thorax 1977; 32:60-2.

28. Caceres CA, Ayers WR. Systems to support clinical decisions: automated medical signal analysis. Med Instrum 1978; 12: 226-9.

29. Fisher PD, Krause GS. Satellite processors lighten the burden in computer-run systems. Electronics 1976; 11: 105-10.

30. Smidt W. On-line Datenverarbeitung in der Lungenfunktions diagnostik. Biomed Tech 1976; 21: 138-40.

31. Holland WPJ, Verbraak AFM, Bogaard JM, Boender W. Effective airway resistance: a reliable variable from bodyplethysmography. Clin Phys Physiol Meas 1986; 7: 319-31.

32. Verbraak AFM, Bogaard JM, Hoorn E, Versprille A. Modelling lung mechanics for the interpretation of bodyplethysmographic tracings; the serial lung model. In: Vansteenkiste GC and Yound PC, eds. Modelling and Data Analysis in Biotechnology and Medical Engineering. Amsterdam: North-Holland Publishing Co. 1983, 165-74.

33. Kars AH, Goorden G, Stijnen T, Verbraak AFM, Bogaard JM. Determinants of the expired $\mathrm{CO}_{2}$-volume curve in normals and emphysema patients. Eur Resp $J$ 1989; 2: $317 \mathrm{~s}$.

34. Friedman RB, Gustafson DH. Computers in clinical medicine; a critical review. Comp Biomed Res 1977; 10: 199-204. 